\title{
EFFECT OF EMBEDDED DELAMINATIONS ON IMPACT BEHAVIOR OF LAMINATED COMPOSITES
}

\author{
Eray SABANCI ${ }^{1}$, Ramazan KARAKUZU2 ${ }^{*}$ \\ ${ }^{1}$ Deparment of Mechanical Engineering, Engineering Faculty, Tunceli University, 62000, Tunceli \\ esabanci@tunceli.edu.tr \\ ${ }^{2}$ Department of Mechanical Engineering, Engineering Facult, Dokuz Eylül University, 35397, Izmir \\ ramazan.karakuzu@edu.tr
}

Abstract

In this study, the influence of size and location of embedded delamination on impact behavior of laminated composite was investigated, experimentally. The specimens were produced as for with and without delamination by vacuum assisted resin infusion molding method (VARIM). CEAST-Fractovis plus impact test machine was used in the experiments. As a result of the experiments, the location of delamination on the impact behavior was seen to be more effective than the size of delamination.

Keywords: Laminated composites, Embedded delamination, Impact behavior.

\section{Introduction}

In recent years, composite materials have been widely used in almost all engineering fields such as automotive, aerospace, civil engineering structures compared to traditional metallic materials, due to their higher stiffness/weight and strength/weight ratios. For example, some parts of vehicular body are constructed composite materials instead of the steel. Therefore, composite materials may be exposed to impact loading with different energy levels according to the usage fields. For instance, during the manufacturing process or maintenance, tools can be dropped on the structure of the aforenamed industries [1]. In this case, although impact velocities are small, the influence of the mass is larger. One of the properties of the laminated composite structures is more susceptible to impact damage than similar metallic structures. During curing process of composite material, embedded delamination may be existed in the interface of layers. If a composite laminate is subjected to low-velocity impact, invisible damage consisting of internal delamination might be also occurred. This internal damage can cause severe reductions in strength and can grow under load. As results of this, many researchers have presented numerous studies to investigate the impact behavior of composite materials.

Hosur et al., [2] presented an experimental study to determine the response of four different combinations of hybrid laminates subjected to low velocity impact loading. They also investigated carbon/epoxy and glass/epoxy laminates to compare the response of hybrid laminates by using vacuum assisted resin molding process. Zheng et al., [3] investigated the effect of permanent indentation on the delamination threshold for small mass impacts on composite structures which caused by hailstones and runway. The characterization of high and low speed impact damage in carbon fiber reinforced plastics was investigated by Symons [4]. The effects of variable impact energy and laminate thickness on the low velocity impact damage tolerance of GFRP composite laminates were examined by Datta et al., [5]. They also determined critical values of impact energy and laminate thickness.

Baucom et al., [6] presented an experimental study to examine the effects of reinforcement geometry on damage progress in woven composite panels under repeated impact loading. An experimental investigation was made to examine the material behavior and low velocity impact performance of fiber reinforced composites by Evci and Gulgec [7]. Freitas et al., [8] carried out a numerical study to examine the failure mechanism in composite specimens subjected to impact loading. Karakuzu et al., [9] carried out both experimental and numerical analysis to examine some parameters such as the effects of impact energy, impactor mass and impact velocity on the maximum contact force, maximum deflection, contact time, absorbed energy, and overall damage area of glass/ epoxy laminated composites. Aslan et al., [10]-[11] presented a numerically and experimentally study to investigate the effects of the impactor velocity, thickness and in-plane dimensions of target and impactor mass on the response of laminated composite plates under low velocity impact. Sabancl and Karakuzu, [12] investigated the impact behavior of laminated composites with embedded delaminations.

In this study, the influence of size and location of embedded delamination on impact behavior of laminated composite was investigated, experimentally.

\section{Material and Method}

\section{$2.1 \quad$ Fabrication of Test Specimens}

The composite laminate used for this study was manufactured by using vacuum assisted resin infusion molding method (VARIM). As matrix materials, the mixture of Durateks DT E 1000 epoxy and Durateks DT S 1105 hardener resin, and as reinforcement materials, unidirectional E-glass fabric with a weight of $300 \mathrm{~g} / \mathrm{m}^{2}$ were used. Mass ratios of the mixture of 
Durateks DT E 1000 epoxy and Durateks DT S 1105 hardener resin were chosen $3 / 1$. The size of test specimens which consist of 12 plies is $100 \times 100 \mathrm{~mm}$, and its stacking sequence is $[0 / 90]_{6}$. Thicknesses of specimens were approximately $3 \mathrm{~mm}$. The diameters of embedded delaminations were selected as 13,20 and $26 \mathrm{~mm}$.

The manufactured specimens with and without delamination can be seen in Figure 1. Differences between the test specimens are delamination size and location. Namely, delaminations, which size are $13 \mathrm{~mm}$, were placed in the identified interface as $2^{\text {nd }}, 4^{\text {th }}$, and $6^{\text {th }}$ from bottom layer (Figure 2). Delaminations which were placed in the interface are illustrated in the Figure 2. Where, for example, C13d2 shows composite with embedded delamination, diameter of $13 \mathrm{~mm}$ and placed in the $2^{\text {nd }}$ interface from bottom layer. Also, $\operatorname{cod} 2$ means that the specimen was manufactured without embedded delamination.

\subsection{Impact Testing Machine}

In this study, CEAST-Fractovis Plus impact tester was used for low velocity impact tests. This machine is a test system which suitable for a wide variety of applications range from low to high impact energies. The impactor, which is a hemispherical steel rod at the end, has a radius of $12.7 \mathrm{~mm}$, is connected to a $22.24 \mathrm{kN}$ force transducer. To avoid the repeated impact on the specimens, an anti-rebounding system which stops the impactor includes in the test instrument. And data acquiring system (DAS) was used to record the history of impact event.

\section{Experimental Results and Discussion}

During the impact tests, the energy is incrementally raised from impact energy level of 5 up to $50 \mathrm{~J}$. In order to examine the size and location of delamination effects on the impact behavior of glass/epoxy laminated composites, each of the impact tests are carried out by using the specimens which manufactured with and without embedded delamination. In order to investigate the effects of embedded delamination on the impact behavior of laminated composite, contact forcetime and contact force-deflection histories were obtained with the help of data acquisition system (DAS). Five different experiments were performed at the same energy level and the same experiment condition due to adverse events that may be occurring during the test. So, total of 160 experiments were performed.

Figure 3a-b represents contact force-time and contact forcedeflection curves for specimens of $\mathrm{C} 13 \mathrm{~d} 2$. In the impact tests for size of delamination, the impact energies were selected as $5,10,20,30,40$ and $50 \mathrm{~J}$.

From Figure 3a-b, it can be said that the impact energy levels of 5 and $10 \mathrm{~J}$ have not any clearly effects on impact behavior. Thus, in the impact tests to examine the effect of location of delamination, the impact energies were selected as $20,30,40$ and $50 \mathrm{~J}$.

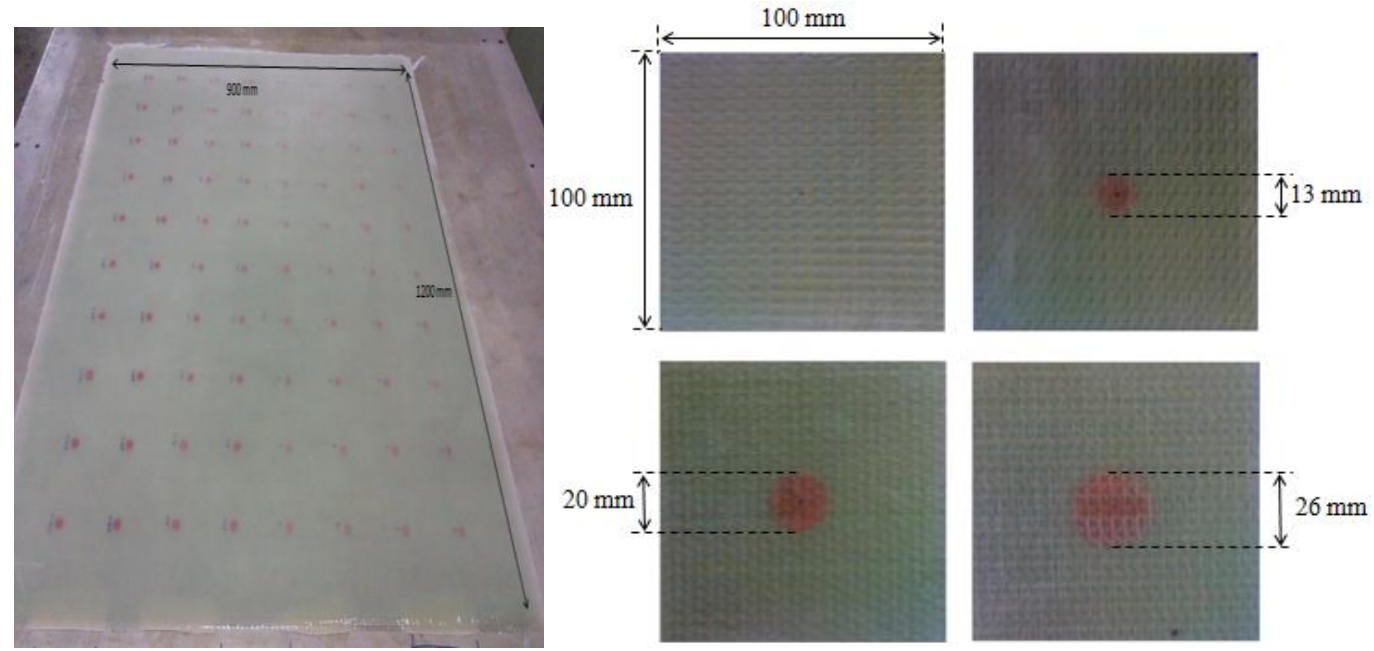

Figure 1: Composite laminate and test specimens.
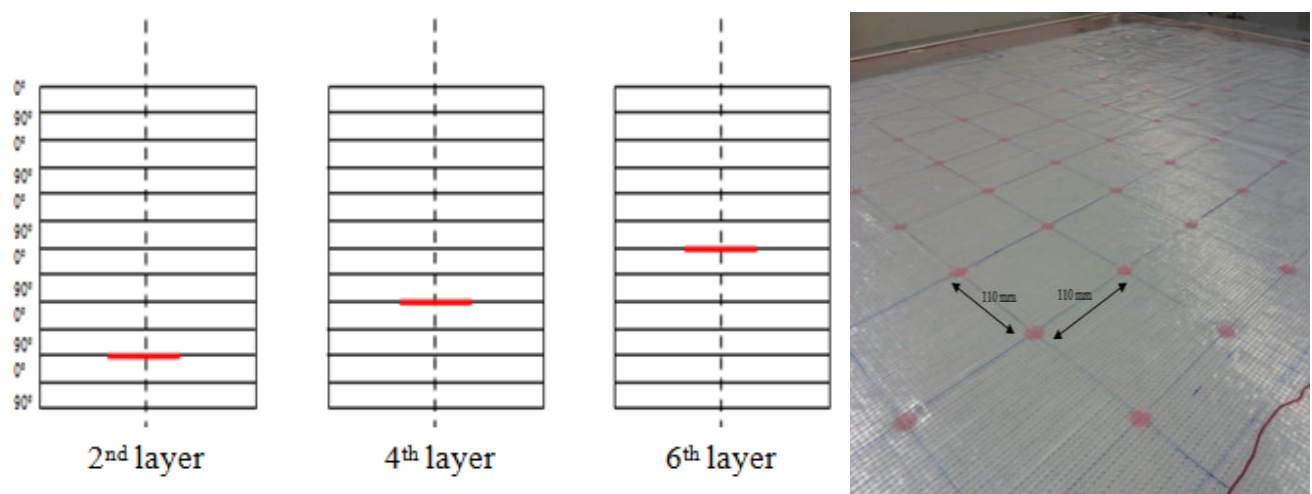

Figure 2: Schematic illustrations of composite with embedded delamination through the thickness for where placed in the interface and a photo for the placed delamination. 
Before evaluating the experiments results, rebounding, penetration and perforation events should be identified. In the most common, rebounding can be defined as the impactor rebound from the specimens at the end of impact events. Penetration event can be defined that the impactor sticks into specimens and does not rebound any more. And also, perforation can be defined as the impactor is stick into specimens and reaches the other side of specimens. For rebounding case, in unloading part, the deflection curves need to be return parallel to loading part. But, for penetration case, the deflection curves do not return parallel to loading part. Accordingly, the deflection curves can be defined as closed for rebounding case.

From the Figure $3 a-b$, it clearly can be said that the contact force is increased by increasing the impact energy level. In addition to this, the impact time increases by increasing impact energy level except for 5 and $10 \mathrm{~J}$.

As seen in Figure 3a-b, the contact force is little changed by the increasing energy level among of the 30 and $50 \mathrm{~J}$. Also, when the peak contact force occurred, time is called peak time and changes by the increasing energy level except for 5 and $10 \mathrm{~J}$. Besides, the maximum deflection is obtained at energy level in $50 \mathrm{~J}$. It can be said that the deflection of specimen increases by increasing energy level. In loading part, the deflection curves are followed parallel to each other. Therefore, it can be comment that the bending stiffness is the same for all case. However, in the unloading part, the curves are shown differs from the each other because of the different damage mechanisms. So, contact time and deflection value changes depending on the different energy levels.

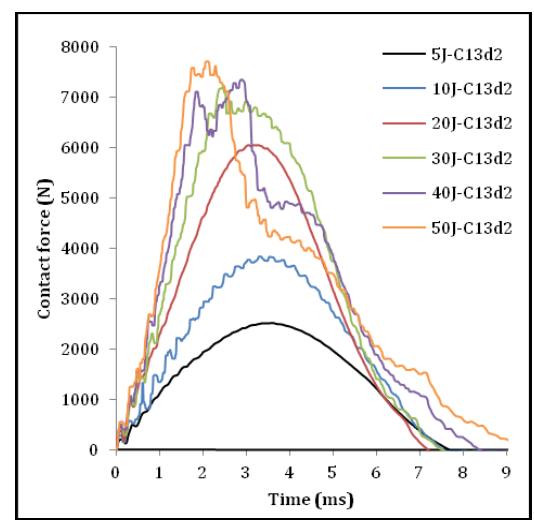

a

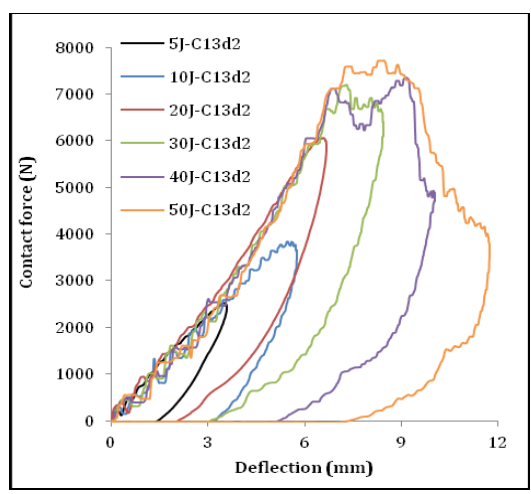

b

Figure 3: (a) The contact force-time and (b) the contact forcedeflection history for specimen of $\mathrm{C} 13 \mathrm{~d} 2$ at the all energy level.
The absorbed energy can be determined from the area under the contact force-deflection curve. The absorbed energy means the total energy that is transferred from the impactor to the specimen. In rebounding case, the amount of energy is returned by the impactor from the specimen depending on the elastic reinstatement. But, for the penetration case, there is no elastic energy returning to impactor. Besides, delamination partly increases with increasing impact energy depending on the absorbed energy.

The graphics of the contact force-deflection which are obtained at the different impact energy can be considered as response of composite materials to impact loads. Figure 4.a-d shows the contact force-deflection curves for impacted specimens depending on the both delamination size and location at the energy levels of 30 and $50 \mathrm{~J}$. As seen from the Figure 4, the types of the all curves can be defined as closed.

Figure 4.a-b expresses the contact force-deflection history for the size of delamination (no delamination, 13, 20 and $26 \mathrm{~mm}$ ). From the result of the Figure $4 a-b$, it can be stated that the maximum contact force and maximum deflection increases by increasing the impact energy level. This is the expected result. In loading part, bending stiffness is nearly the same for all cases. But unloading part is different from each other because of the different failure mechanism for $50 \mathrm{~J}$. As a result of these, the size of delamination has not any significantly effect on the contact force and deflection for impact energies of 30 and $50 \mathrm{~J}$. Figure 4.c-d represents the contact force-deflection history for the locations of delamination which placed in $2^{\text {nd }}, 4^{\text {th }}, 6^{\text {th }}$ interface. It is clear from Figure 4.c-d that bending stiffness is different from each other in loading part. Unloading part is also different. The deflection is the maximum in the $2^{\text {nd }}$ interface at the same impact energy level while contact force is nearly the same. The maximum contact force and maximum deflection also rise by increasing the impact energy. As a result of these, the location of delamination has more effect than the size of delamination.

Figure 5 shows variation of the absorbed energy depending on the size and location of delamination. From the Figure 5, it can be said that the variation of the absorbed energy is nearly constant depending on the size of delamination at the impact energy level of $20 \mathrm{~J}$. However, for the higher delamination diameter, absorbed energy decreases at the impact energy level of 40 and $50 \mathrm{~J}$ except for $30 \mathrm{~J}$. From the Figure 5.b, absorbed energy is the maximum in the composite with delamination of $2^{\text {nd }}$ interface due to the other interfaces for all the impact energies because of the higher delamination region. In order to show the damage modes, some photographs of damaged specimens for impacted surface (top) and nonimpacted surface (bottom) taken with strong backlighting are given in Figure 6-7. Damage which occurred depending on the size and location of delamination can be seen for the impact energy levels of 30 and 50J. As seen in photographs, damaged area is increased by increasing impact energy and also can be seen that the damage area was overflowed in comparison with the embedded delamination diameters of 13 and $20 \mathrm{~mm}$. Delamination area in the specimen with embedded delamination of $26 \mathrm{~mm}$ in $2^{\text {nd }}$ interface $(\mathrm{C} 26 \mathrm{~d} 2)$ is greater than those of the others for impact energy level of $30 \mathrm{~J}$. So, absorbed energy in $\mathrm{C} 26 \mathrm{~d} 2$ specimen is also higher than the other ones. At the 50J impact energy, failure areas in $2^{\text {nd }}$ interface are similar to each other. When the failure areas and contact force-deflection curves are examined, it can be said that damage mode is also rebounding mode. 

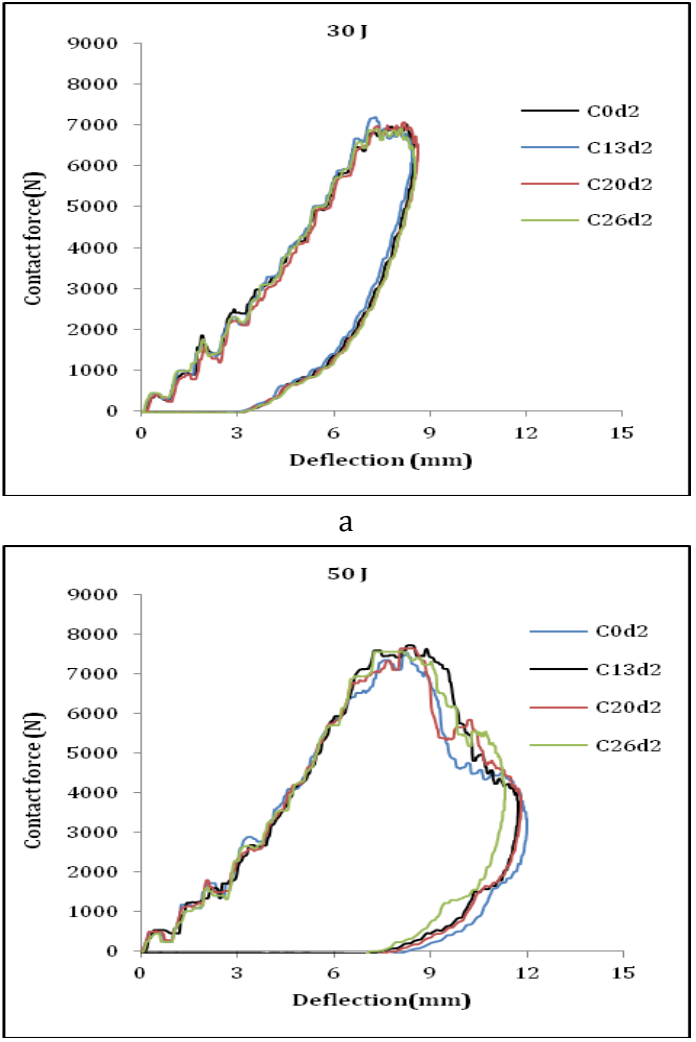

b

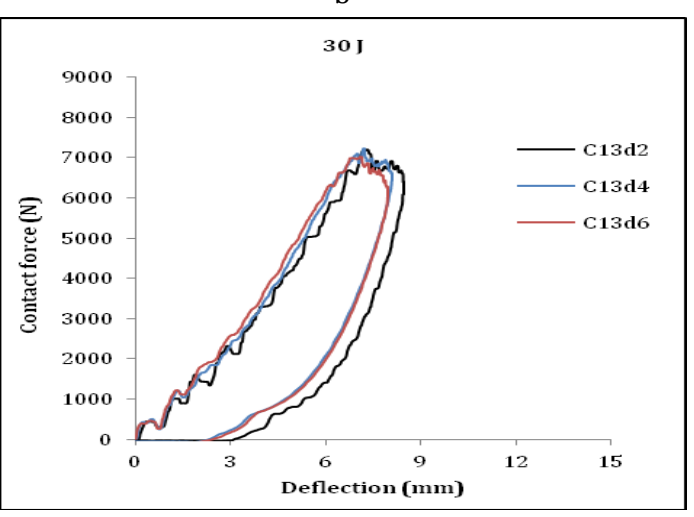

c

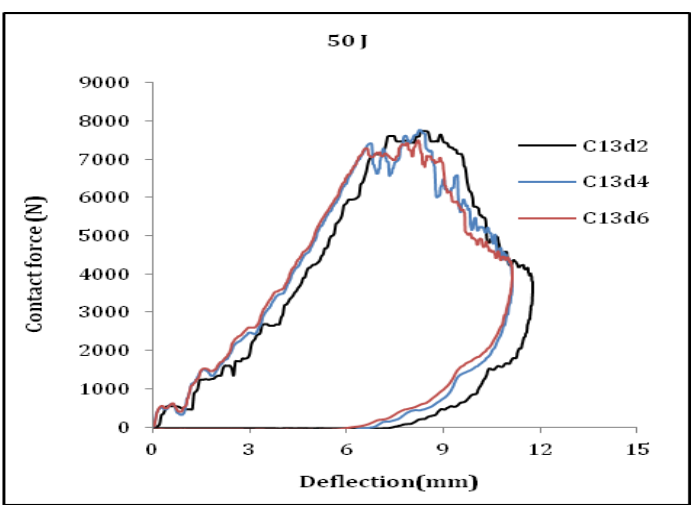

d

Figure 4: Contact force-deflection curves for, a-b) delamination diameters of $0,13,20,26 \mathrm{~mm}$ in the $2^{\text {nd }}$ interface, c-d) delamination location of $2^{\text {nd }}, 4^{\text {th }}$, and $6^{\text {th }}$ interfaces from bottom layer for delamination diameters of 13 $\mathrm{mm}$ subjected to the impact energy of 30 and 50J.
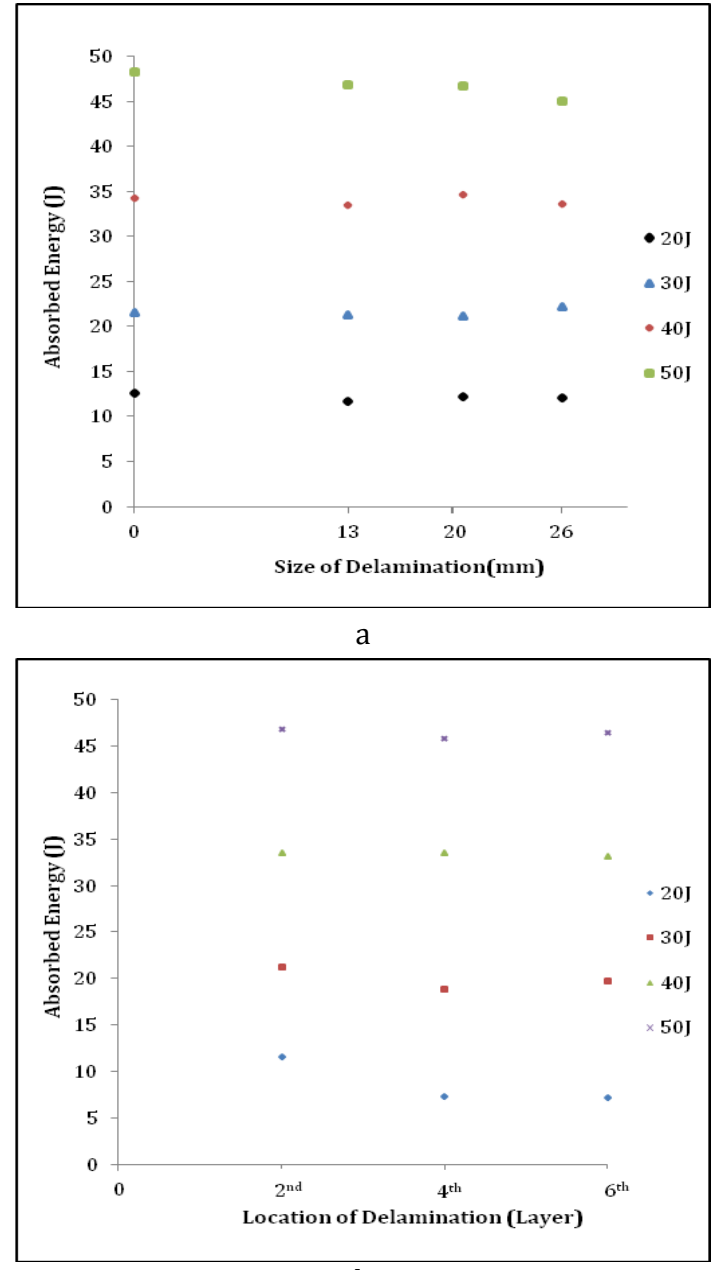

$\mathrm{b}$

Figure 5: The variation of absorbed energy depending on, a) size of delamination in $2^{\text {nd }}$ interface, b) location of delamination for delamination diameter of $13 \mathrm{~mm}$.

\section{Conclusion}

This study presents the influence of size and location of embedded delamination on impact behavior of laminated composite, experimentally.

In order to investigate the impact behavior of laminated composite with embedded delamination, some experiments were performed.

The concluding remarks drawn from this study can be summarized as:

- The contact force and time is raised by increasing impact energy levels except for 5 and $10 \mathrm{~J}$.

- The maximum value of deflection is increased by increasing impact energy levels.

- The maximum contact force and maximum deflection are not significantly changed depending on the size of delamination for the same energy level

- The maximum contact force and the maximum deflection are little changed depending on the location of delamination for the same size of delamination and the same energy level.

- The location of delamination on the impact behavior is seen to be more effective than the size of delamination. 


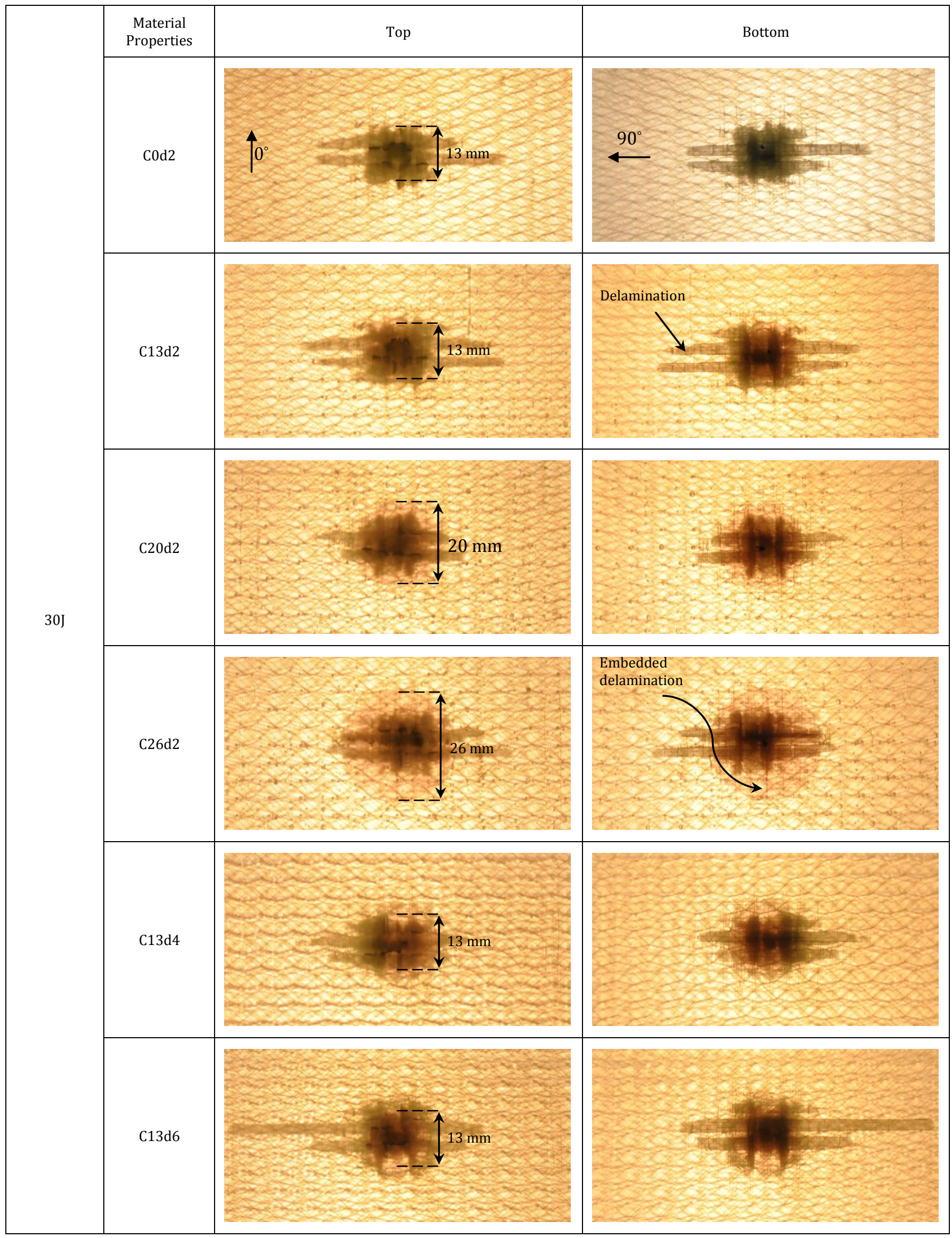

Figure 6: Top and bottom images of damage zones of specimens for impact energy level of $30 \mathrm{~J}$. 


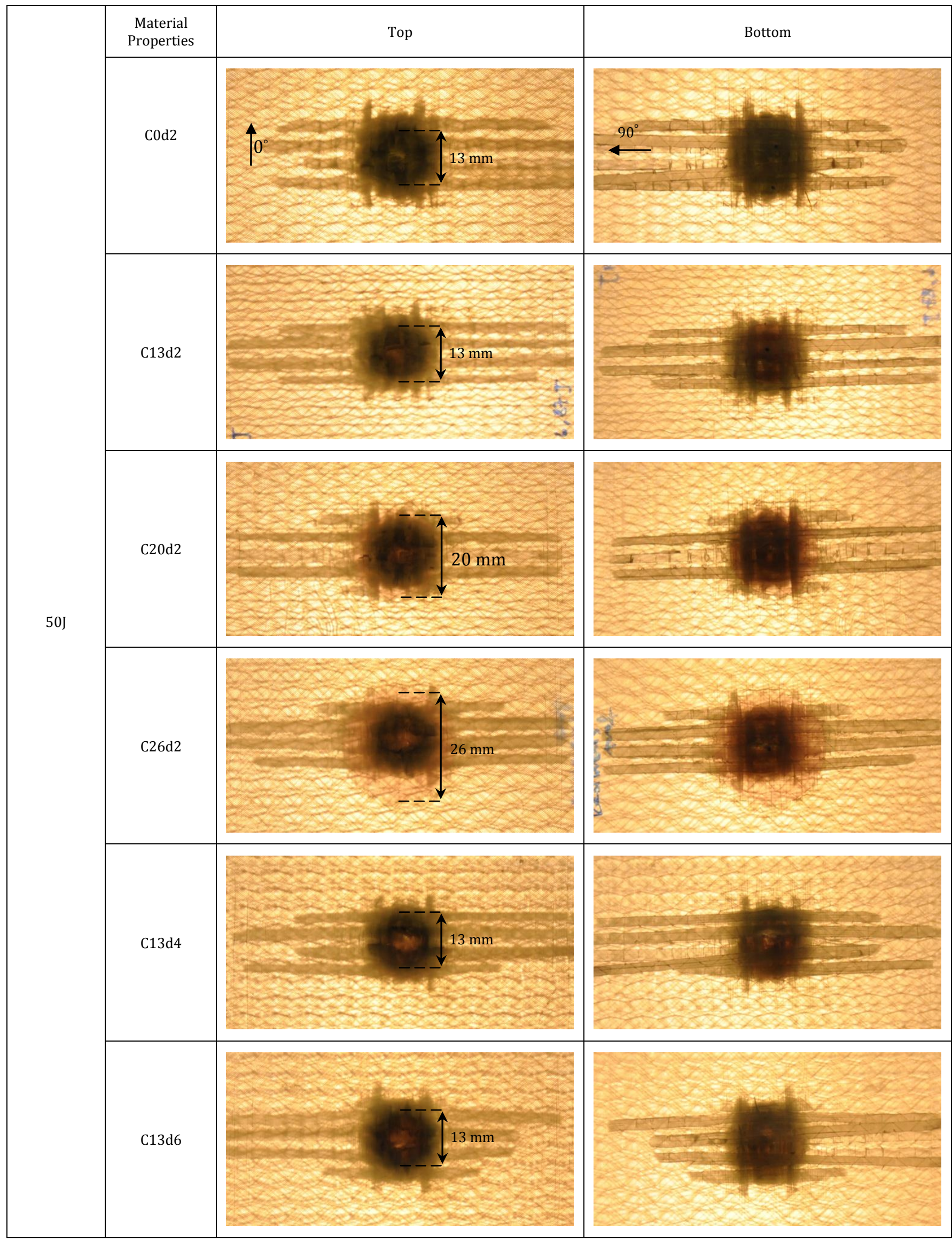

Figure 7: Top and bottom images of damage zones of specimens for impact energy level of $50 \mathrm{~J}$. 
- The common damage mode is observed as delamination and matrix cracks but rather fiber fractures less than roughly impact energy level of $30 \mathrm{~J}$. Also, there is some fiber fractures accompanied by delamination and matrix cracks for higher than approximately impact energy level of $40 \mathrm{~J}$.

- Rebounding damage mode is observed at the all energy levels.

- The maximum value of the absorbed energy is observed in the impact experiments which performed by using the specimen of $\operatorname{Cod} 2$ owing to the elastic behavior of specimen depending on the size of delamination at the energy level of $50 \mathrm{~J}$. Thus, it can be comment that the maximum damaged area is occurred into the specimen of $\mathrm{C} 0 \mathrm{~d} 2$.

- Also, depending on the location of delamination, the maximum value of the absorbed energy is detected in the impact experiments which used the specimen of C13d2. Thus, it can be said that the embedded delamination in the $2^{\text {nd }}$ interfaces from bottom layer has higher delamination region than the other interfaces.

- The non-impacted face damage area of specimen is observed much bigger than the impacted face as depending on tensile crack by bending and delamination of back part of the plate.

- Damage area is increased by increasing impact energy levels and also it can be seen that damage area was overflowed in comparison with the embedded delamination diameters of 13 and $20 \mathrm{~mm}$.

\section{References}

[1] Abrate, S., Impact on Composite Structures, Cambridge University Press, Cambridge, 1-5, 1998.

[2] Hosur, M. V., Adbullah, M. and Jeelani, S., "Studies on the low-velocity impact response of woven hybrid composites", Composite Structures, 67, 253-262, 2005.
[3] Zheng, D. and Binienda, W. K., "Effect of permanent indentation on the delamination threshold for small mass impact on plates", International Journal of Solids and Structures, 44, 8143-8158, 2007.

[4] Symons, D. D., "Characterization of indentation damage in 0/90 lay-up T300/914 CFRP", Composites Science and Technology, 60, 391-401, 2000.

[5] Datta, S., Krishna, A. V. and Rao, R. M. V. G. K., "Low velocity impact damage tolerance studies on glass/epoxy laminates-effects of material, process and test parameters", Journal of Reinforced Plastics and Composites, 23(3), 327-345, 2004.

[6] Baucom, J. N. and Zikry, M. A., "Low-velocity impact damage progression in woven E-glass composite systems", Composite: Part A, 36, 658-664, 2005.

[7] Evci, C. and Gulgec, M., "An experimental investigation on the impact response of composite materials", International Journal of Impact Engineering, 43, 40-51, 2012.

[8] Freitas, M., Silva A. and Reis L., "Numerical evaluation of failure mechanisms on composite specimens subjected to impact loading", Composite: Part B, 31(3), 199-207, 2000.

[9] Karakuzu, R., Erbil, E., Aktas, M., "Impact characterization of glass/epoxy composite plates: An experimental and numerical study", Composite: Part B, 41, 388-395, 2010.

[10] Aslan, Z., Karakuzu R., Okutan B., "The response of laminated composite plates under low velocity impact loading", Composite Structures, 59, 119-127, 2003.

[11] Aslan, Z., Karakuzu R. and Sayman O., "Dynamic characteristics of laminated woven E-glass-epoxy composite plates subjected to low velocity heavy mass impact", Journal of Composite Materials, 36, 2421-2442, 2002.

[12] Sabancl, E. and Karakuzu, R., "Impact behavior of laminated composites with embedded delaminations", $14^{\text {th }}$ International Materials Symposium, 2012, 606-613. 